\title{
Multivariate Statistic Analysis of the World Population Ageing
}

Bagautdinova N.G.

Panasyuk M.V.

Pudovik E.M.

Gilmanova A.A.

Kazan Federal University, Institute of Management, Economics and Finance, Kazan, 420008, Russia

Email address: epudovic@mail.ru

\section{Doi:10.5901/mjss.2014.v5n28p50}

\begin{abstract}
The research is devoted to the issue of the ageing of population, which is one of the global problems of the modern world. World countries have been grouped according to the amount of people over 65 years old. The conclusions about spatial differentiation of the ageing population have been drawn. The groups of states with a different level of population ageing were singled out. The amount of ageing population have been forecasted.
\end{abstract}

Keywords: ageing of population, demographic load, cluster analysis, forecast, age structure of population.

\section{Introduction}

Population ageing is becoming one of the global problems of the modern times. In 1950-s 60-70\% of the world states had a large portion of young population, a small share of mature people and even a smaller part of elderly population [1]. Ageing of population is closely associated with increased life expectancy, which was mainly determined by better quality health services, new discoveries in pharmaceutics, children diseases treatment, as well as increased standard of living in comparison with antebellum period. Later the percentage of the young in the societies of the world states started to decrease, but the share of mature and old population began to grow [2]. The increase in the share of elderly and old people in the population structure stipulates the necessity of studying them, their needs, demands, biological and social possibilities. Demographic ageing is becoming a national problem that demands certain solution nowadays and extensive training in the nearest years.

In social sphere, ageing of population affects family structure and living conditions, housing needs, migration tendencies, epidemiologic situation and medical aid needs. In the political sphere, population ageing may influence election results and the system of political representation $[3,4]$.

In demographic science, two types of population ageing can be distinguished - aging "from below" and aging "from above". With population, aging mainly takes place "from below" because of a lower birth rate. This type is characterized by the decrease in the number of children and teenagers and young population in general. As a result, the scope of senior age groups increases.

Ageing "from above" happens as the result of reduced mortality, which increases the population's life expectancy and the size of senior age groups. With decreased mortality, senior age groups begin to live longer. In developed countries population ageing considerably happens both "from below" and "from above". Therefore, these countries have a low birth rate and achieve the characteristics of high life expectancy. In 2008, the average life expectancy in Japan was 82.15 years, in Singapore - 82 and in France 81 years $[5,10]$.

Population ageing has both economic and social implications. The share of senior citizens increases. Pension funds bear the burden of pension payments. Meanwhile, the scope of labor power that contributes to these funds decreases. In most developed countries, the population retires at the age of 65 . Thus, in Western countries the demographic load on the employable population is reduced $[6,7]$.

Ageing of population also influences economic development of a country. Currently ageing is typical of almost all developing countries. Lowered birth and death rates and increased life expectancy lead to the increase of the total number of elderly people. The amount of elderly people in the world increases faster than total population. The process of 
population ageing is different in developed and developing countries. In developed countries, the relative share of old people started to decline after it had achieved a considerable level. In developing countries it continues to grow and will stop only when the society achieves a higher level of industrial development.

In developing countries, the rates of population ageing are higher than in developed countries. Consequently, developing countries will have less time to adjust to the consequences of population ageing. In developing countries, the ageing of population takes place against the background of a much lower level of social and economic development than in advanced countries.

Heterogeneity of developmental character and its stages, trends of ageing and displayed distinctions stipulated the necessity of its complex study [7, 9].

\section{Grouping the Countries According to Age Distribution of People over 65 Years Old}

To analyze the processes of ageing the grouping of 195 countries according to the amount of people older than 65 in 2003 and 2011 has been done. The method of data mining (classification) has been applied.

In 2003, the countries were objectively divided into 5 groups:

I. the group of countries with young population (the share of population over 65 is less than 4\%);

II. the group of countries with transitional age structure (the share of the population over 65 is 4.1-8\%);

III. the group of countries with mature population (the share of population over 65 is 8.1-12\%);

IV. the group of countries with elderly population (the share of population over 65 is 12.1-16\%);

V. the group of countries with old population (the share of population over 65 is 16.1-20\%).

The share of countries from Group I was 33\% of all countries analyzed. This group includes countries with developing economy and the Fourth World countries with underdeveloped economy. The highest rate of young population (4\%) takes place in Pakistan, Belize, Central Africa and Nicaragua. The smallest share of population over 65 years old lives in the United Arab Emirates, where the index of population ageing is $1 \%$.

The share of Group II is $25 \%$ of all countries and it includes countries with developing economy. The highest rate in the group belongs to Albania (8\%), where the standard of living is increasing owing to favourable climatic conditions, environment, growing tourism, which influences the development of infrastructure and the appearance of new services. In general, this leads to improvement of living standards. The lowest rate belongs to Guatemala, Haiti, Honduras and Malaysia (4.1\%).

Today developing countries represent the most numerous group of countries, which sometimes differ essentially from each other by per capita income, structure of economy, social structure. $8 \%$ of countries with developed and developing economy belong to the group of countries with mature population. The highest rate of demographic ageing (11.9\%) belongs to New Zealand. The lowest rate belongs to such countries as Aruba and Singapore (8.3\% accordingly).

The share of countries from Group IV is $12 \%$. In the group of countries with elderly population, the highest and the lowest rates belong to developed countries - Great Britain (15.9\%) and the USA (12.3\%) accordingly.

$7 \%$ of states belong to the group with old population, which includes mainly developed countries. Developed countries dominate in the world economy. This can be testified by the combination of factors: GDP volume in general and per capita, income level, share in the world trade, education level, workforce productivity etc. The countries with the oldest population are Italy (19.2\%), Japan (18.8\%),Germany (18\%). Estonia has the lowest rate in the group with 16.2\%.

In 2003, the youngest state from ageing point of view was the United Arab Emirates. The share of people over 65 years old was just $1 \%$ of total population. The oldest state was Italy (with $19.2 \%$ of people over 65 ).

In 2011, the world countries were divided into 6 groups. The sixth group was objectively singled out from Group V.

$28 \%$ of 195 countries analyzed refer to Group I of countries with young population, which is 5\% lower than in 2003. 54 countries held their position in Group I, 10 countries withdrew from the group, one country from Group II joined. These are countries like Botswana, Haiti, Mongolia, Nepal, Pakistan and others. The leading position in the group belongs to Jordan (4\% of people over 65 years old). The United Arab Emirates remains the "youngest" country in respect of population, having lowered its rate from 1\% in 2003 to $0.4 \%$ in 2011.

In comparison with 2003, the group of countries with transitional age structure increased insignificantly (1\%). Group II included 26\% of countries: 10 countries joined from Group I, at the same time 7 countries quitted mainly to Group III and one country to Group I. For this group of countries the lowest rates of population ageing process were registered for Turkmenistan and Mongolia (4.1\% each), with the highest rate for Jamaica (7.9\%).

The following changes were traced in the group of countries with mature population: 11 countries steadily maintained their position, 7 countries joined from other groups and 5 countries (Hong Kong, Iceland, New Zealand and others) experienced changes in their population structure, whereupon they proceeded to other groups. Group III 
comprised $9 \%$ of countries, which is $1 \%$ higher than in 2003. The leading position in the group is held by Macedonia $(12 \%)$, and a low rate of population ageing can be observed in China and Sri-Lanka (8.4\%).

For the group of countries with elderly population the following phenomena are typical: 17 countries have remained in the group since 2003, 5 countries joined and only 7 countries were allocated to other groups. Comparing with 2003, we observe the decrease in the number of countries in this group to 1\%. The highest rate of population over 65 years old in Group IV belongs to the Netherlands (15.8\%) with the lowest rate in Iceland (12.2\%).

Group V unified 9\% of countries out of 195. 7 countries (Austria, Great Britain, Switzerland, Finland and others) joined from Group IV in 2011, 10 countries maintained their positions since 2003 and 3 countries with the 20\% share of population over 65 years old objectively differentiated to Group VI. The highest rates in the group belong to Greece (18.7\%) and lowest belong to Lithuania (16.2\%).

Group VI appeared in 2011, it comprises three economically developed countries. These are Germany with its increase from 18\% in 2003 to $20.6 \%$ in 2011, Italy with 19.2\% to 20.6\% in 2011 and Japan with the increase from 18,8\% to $23.4 \%$ accordingly.

The maximal value of population ageing rate takes place in Japan (23.4\%), while the minimal value belongs to the United Arab Emirates (as in 2003), but with the lower ageing coefficient (0.4\%).

The following changes took place in 2011 in comparison with 2003: the transfer of some countries from Group I with young population to Group II (Haiti, Mongolia, Nepal, Pakistan, South Africa, Zimbabwe and others). For 8 years, these countries experienced population growth of people over 65 , therefore living conditions in these countries improved. The transfer from the group of countries with transitional age structure to Group III took place in Albania, Chile, China, Indonesia, Korean Democratic People's Republic and so on. Cuba, Hong Kong, Iceland, New Zealand and others proceeded from the group of countries with mature population to Group IV. The transfer from the group of countries with elderly population to the group of countries with old population took place in Austria, Finland, Slovenia, Switzerland, Great Britain etc. Three countries with developed economy (Germany, Japan, Italy) transferred from Group V to Group VI.

Thus, the situation with ageing of population in the world is the following: in the least developed countries young population prevails, the process of population ageing in these countries passes slowly. In the most developed countries the process of ageing is an urgent problem. According to the UN population ageing scale, since 2001 the world total population refers to the category of old population. According to the Cenrtal Bank's data, the share of people over 65 years old was $6.4 \%$ in 1994, and it increased to $7.7 \%$ in 2011. The amount of incapacitated population was just 15 million people in the middle of the XX century, and in 2012 it approached the amount of 115 million. It is expected that this amount will exceed 400 million people by 2050 , according to the UN average alternative forecast.

\section{Population Aging Forecast}

The increase in the share of elderly people among the total population states serious moral and socio-economic problems for the society. The influence of population ageing on economics can reveal itself in the following directions:

1. employment and qualitative composition of work force;

2. pension provision and elderly people's living standards;

3. health, social service and health care organizations.

Based on the World Bank's data from 1993 to 2011 on the share of population older than 65 in 195 countries of the world, forecasting was conducted in order to determine stable trends of increasing population ageing process in the world. The prognosis was carried out by means of extrapolation method for a short-term period (5 years).

According to the data in the prognosis, it is obvious that we observe a steady growth of population ageing in the world from 1993 to 2016. Although there are countries where the ageing process demonstrates insignificant growth, these are mainly the Fourth World countries. 


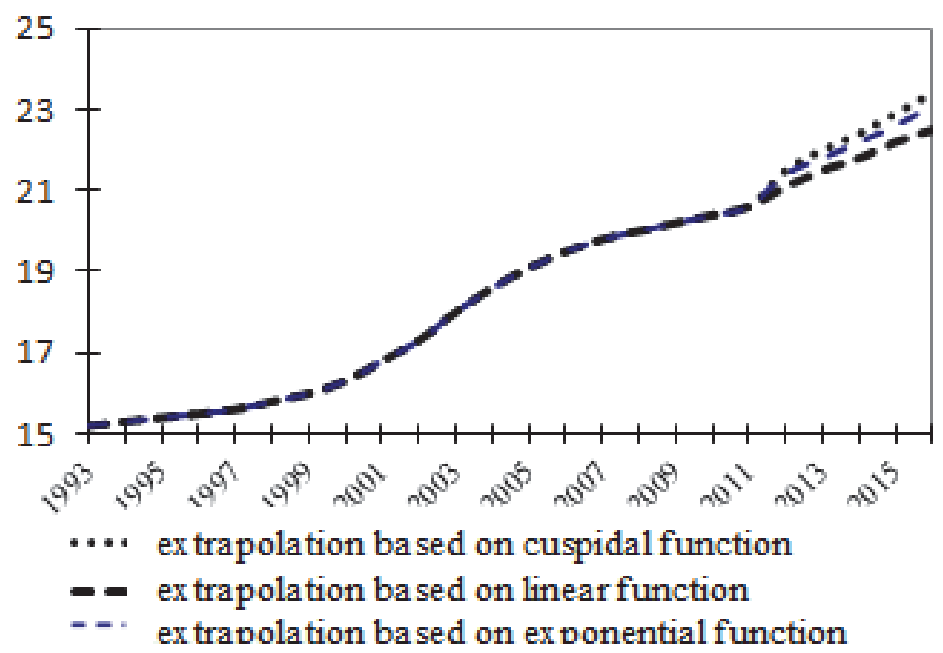

Figure 1. The share of people over 65 in Germany, \%.

At the same time there is a number of states in the world where the ageing process takes place very rapidly. It may be expected that social and economic implications of this event will emerge most distinctly in the near future. This group of countries includes Germany, Japan and Italy. Russian Federation is about to enter this group as well.

In the Federal Republic of Germany the process of ageing takes place more rapidly than in other countries of the European Union. Approximately one in five citizens in the country has attained the elderly age of 65 years. According to the UN data, the share of elderly people in Germany in 2011 comprised one of the highest rates $-20.6 \%$. As can be seen from the prognosis, the growth of senior citizens (that is, the process of ageing) will increase from $20.6 \%$ in 2011 to $23.4 \%$ by 2016, according to the extrapolation method based on the cuspidal function (Fig.1). As the result of demographic ageing, we can observe the increase and economic load on working-age population.

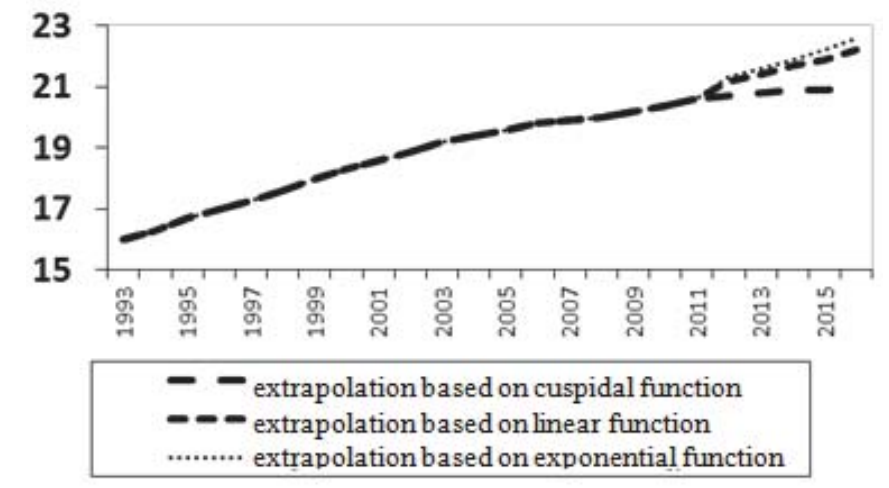

Figure 2. The share of people over 65 in Italy, \%.

In Italy the problems of population ageing are also in the focus of the government's attention. This generally implies that Italian population is ageing rapidly, there is the growth in the number of people over 65 and older, whereas birth rate and the amount of the underage decreases. The causes of this lie both in social and religious spheres because, on the one hand, insufficient support of young families by the government, and, as a result, the process of childbearing, hinder the early start of a family life. On the other hand, religious attitudes prevent the growth of extramarital births, which largely smoothers the situation, for instance, in the countries of Northern Europe.

In 2011 the share of people over 65 years old and older was $20.6 \%$ of all population. In accordance with the conducted forecasting methods, a 2\% increase of this rate is expected by the year 2016 and will be $22.6 \%$ (according to the extrapolation method based on exponential function) (Fig.2).

The process of population ageing in Japan is the fastest on the planet. Japan is famous for its long life span and its 
long-living people. $23,4 \%$ of Japanese population, which in 2011 numbered 127.8 million people, refer to a category of over 65 (Fig.3). Extrapolation method based on linear function implies that the process of demographic ageing will increase steadily and by 2016 will amount $25.9 \%$.

The more senior citizens there are the bigger is the load upon the state's financial system. This is revealed most vividly at the time of crises. In the Land of the Rising Sun we are observing the growth of senior population, while the number of birth rates is declining steadily [11].

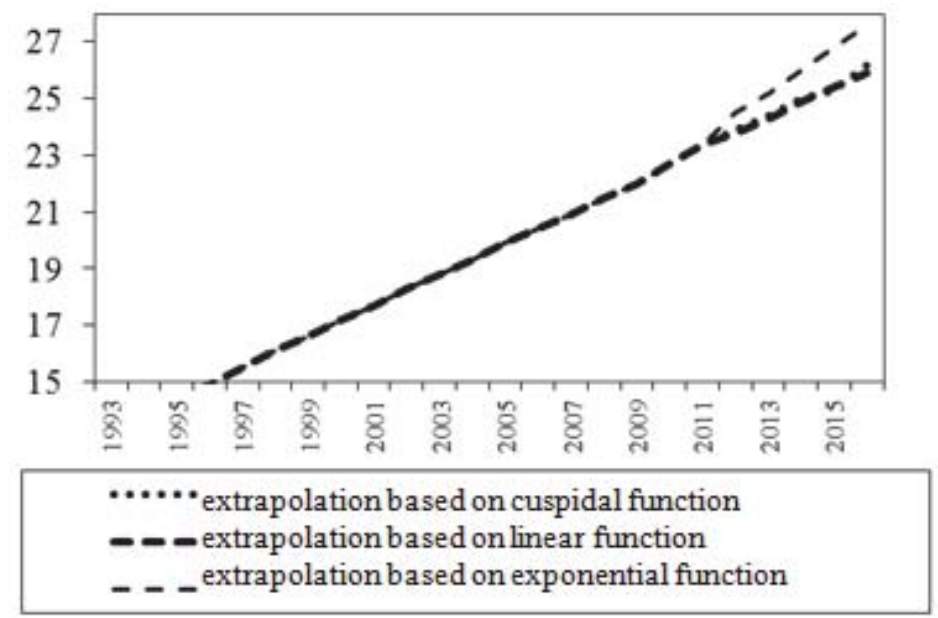

Figure 3. The share of people over 65 in Japan, $\%$

In the Russian Federation, the process of population ageing is characterized by the increasing share of senior citizens with the simultaneous decreasing of children and the working-age people in the total population of the country.

Russia is included into the group of few countries, where, according to forecasting methods, the decrease in the population ageing level is expected (Fig.4). The peak point of the ageing process in the Russian Federation was in 2005, when the rates of demographic ageing amounted $13.8 \%$. According to the preferred prognostic methods accomplished programmatically, it is obvious that in the nearest 5 years the process in this country will be characterized by reduced volume of ageing and by 2016 will comprise 12.1\%. Obviously, this can be explained by the favourable balance of migration. Although it does not mean the situation is improving, as, because of the low birth rate and ageing of existing work-age population, the economic load on the working population will increase [8].

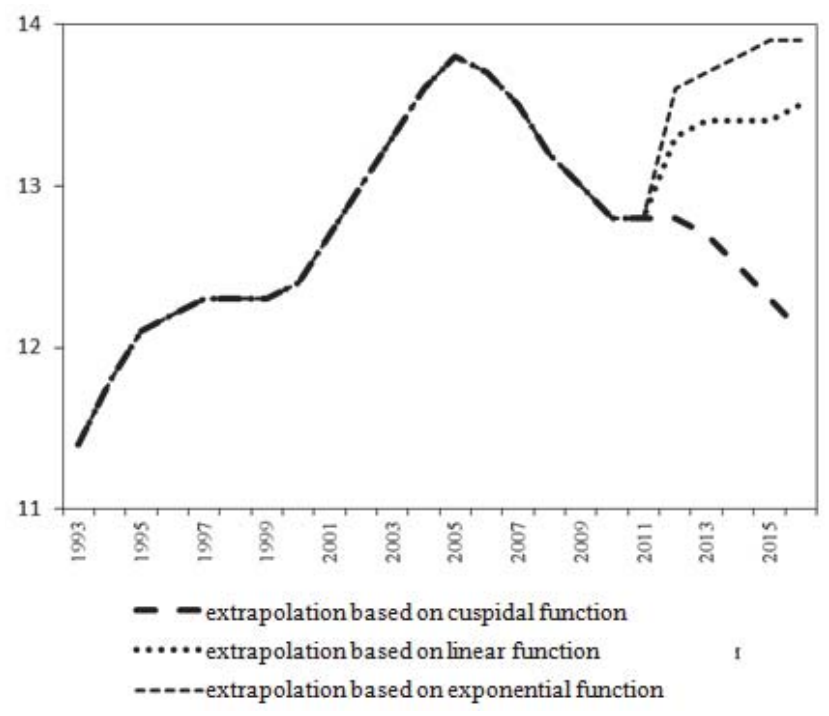

Figure 4. The share of people over 65 in Russia, 
The data received as the result of forecasting in the "Golden Billion" countries lets us claim that the process of population ageing will grow insignificantly within the range of $1-2 \%$ in the nearest 5 years, except the countries where the share of population over 65 was more than $20 \%$ in 2011.

The problem of population ageing is quite significant now and has a dramatic impact on all the spheres of daily human routine, and so it will be henceforth. In the economic sphere, the population ageing will influence economic growth, savings, investments, labour markets, pensions, taxation and transfer of wealth, property and guardianship from one generation to another. Population ageing will affect health and healthcare system, family structure and living conditions, habitation and migration from now onward.

\section{References}

Bloom, D.E., Canning, D. , Fink, G The greying of the global population and its macroeconomic consequences(2010) Twenty-First Century Society Volume 5, Issue 3, November 2010, Pages 233-242

Dowd, J.J., Bengtson, V.L. Aging in minority populations. An examination of the double jeopardy hypothesis (1978) Journals of Gerontology, 33 (3), pp. 427-436.

Joseph, A.E., Cloutier-Fisher, D.Ageing in rural communities: Vulnerable people in vulnerable places (2005) Ageing and Place: Perspectives, Policy, Practice, pp. 133-146.

Keating, N., Phillips, J. A critical human ecology perspective on rural ageing (2008) Rural Ageing: A Good Place to Grow Old?, pp. 1-10.

Kučera, T., Kučerová, O., Opara, O., Schaich, E. (2000) New Demographic Faces of Europe: The Changing Population Dynamics in Countries of Central and Eastern Europe.

Kulcsár, L.J., Brădăţan, C. The Greying Periphery-Ageing and Community Development in Rural Romania and Bulgaria (2014) Europe Asia Studies 66 (5), pp. 794-810

Panasyuk, M.V. Method of integrated assessment of regional system (2014) Mediterranean Journal of Social Sciences, 5 (18 SPEC. ISSUE), pp. 149-152.

Panasyuk, M.V., Dzasaeva, R.D., Shaidullin, R.N., Anopchenko, T.Y. Problems of modernization of the health economics in the russian regions (2013) World Applied Sciences Journal, 27 (13), pp. 154-158. Cited 2 times.

Panasyuk, M.V., Trofimov, A.M., Khrushchev, A.T. Geographical aspects of control of social-economic installations (1989) Vestnik Moskovskogo Universiteta, Seriya Geografiya, 2, pp. 3-8.

Sae, N.a, Yoshio, A.b, Yuji, E The aging population in the suburbs of Metropolitan Tokyo (2006) Japanese Journal of Human Geography, Volume 58, Issue 4, 2006, Pages 63-76

Vogt, G. Care-giver migration to greying Japan (2010) Demographic Aspects of Migration 2010, Pages 327-348.

Razumovskaya, E.M. , Kutsevol, N., Popov, M., Mishakin, T., Leto, L., Tsalikova, V. The effectiveness of management practice in the market of socially important services. Asian Social Science, Volume 10, 28 September 2014, Pages 118-122

Razumovskaya, E.M.,Lapidus, L.V., Mishakin, T.S., Popov, M.L. Features and peculiarities of the Russian passenger rail market development. Mediterranean Journal of Social Sciences vol. 5 (18 SPEC. ISSUE), pp. 165-170.

Mingazova N.M. Modification of Active Learning in Environmental Education Russian Universities. Procedia - Social and Behavioral Sciences Vol. 131, pp. 85-89 // 3rd World conference on educational technology researches Turkey 07-09.11.2013. 